\title{
PERFORMANCE OF UPROOTED BR11 RICE SEEDLINGS STORED UNDER DIFFERENT CONDITIONS
}

\author{
M.A. HAQUE ${ }^{1}$, M.M. KARIM ${ }^{1}$, M.A.HASAN ${ }^{* 2}$ and M.A. KHATUN ${ }^{2}$ \\ ${ }^{1}$ Department of Agronomy, Bangladesh Agricultural University, Mymensingh, Bangladesh \\ ${ }^{2}$ Hajee Mohammad Danesh Science \& Technology University, Dinajpur, Bangladesh
}

(Received: 09 October 2002; accepted: 07 May 2003)

\begin{abstract}
An experiment was conducted at the Agronomy Field Laboratory, Bangladesh Agricultural University, Mymensingh, from July to December 1999 to find the effect of 3 storage conditions on uprooted BR11 rice seedlings viz. under shade, in the sun and in water and 5 storage durations viz. $0,2,4,6$, and 8 days. The storage condition has a significant effect on all the crop characters except the length of panicle and 1000 grain weight. The best performance was exhibited by the seedlings stored in water followed by those stored under shade and in the sun, and the difference was significant in almost each case. The effect of storage period was also significant. A regular trend of decrease in the value of the crop characters was noticed with the increase in the period of storage from 0 to 8 days. In most of the cases, the differences between the treatments were significant. This indicated that delay in transplanting had an adverse effect on crop characters. The interaction of storage conditions and storage durations significantly affected the crop characters and number of hills/plot and culms $/ \mathrm{m}^{2}$ and also harvest index. In general, the effect of interaction was in favour of water storage in all the storage durations, and was followed by storage under shade and in the sun with shorter period of 0 to 2 days of almost all the studied crop parameters.
\end{abstract}

Key words: BR11, performance, storage duration, uprooted seedlings

\section{INTRODUCTION}

Rice (Oryza sativa) is the most important food crop of Bangladesh and it covers about 9.985 million hectares. ${ }^{1}$ The farm activities and economy of the country are almost entirely rice based and the rice crop occupies a place in almost 98 per cent of the existing number of cropping patterns of the country. ${ }^{8}$

Though rice is extensively cultivated in Bangladesh, the yield of only $2.48 \mathrm{t} / \mathrm{ha}$ is much lower in comparison with that of the other rice growing countries like South Korea and Japan where the average yield is $6.01 \mathrm{t} / \mathrm{ha}$ and $6.18 \mathrm{t} / \mathrm{ha}$ respectively. ${ }^{6}$ Though the yield of rice in Bangladesh in general has increased, it is still much lower than the genetic potential yield of about 15-16t/ha in BR11 rice, obtained from international trials. ${ }^{2,4}$ However, the genetic potentiality may not be achieved due to various environmental and socio-economic conditions. Due to unexpected incessant rainfall or flood during the transplanting season, much of the cultivated land, especially the low-lying areas, goes under water

\footnotetext{
"Corresponding author
} 
causing severe damage to the rice seedlings in the nursery beds and in the freshly transplanted fields. As a result, an acute shortage of rice seedlings occurs very frequently when the floodwater recedes. Under such situations, the rice seedlings may be saved by uprooting them from the nursery beds at the advent of flood, and storing in a suitable place until the flood water recedes.

Uprooted rice seedlings are preserved under various conditions such as in water, in the sun, in mud, and under shade, etc. Sometimes, seedlings are transported in bundles inside gunny bags. The viability and strength of uprooted rice seedlings may be adversely affected by variable conditions of preservation. It is not yet clearly known how long the uprooted rice seedlings could be preserved without their quality and vigour deteriorating. The present study was therefore, undertaken to determine the effect of storage conditions and durations on uprooted seedlings and their performance.

\section{METHODS AND MATERIALS}

A study was undertaken at the Agronomy Field Laboratory of Bangladesh Agricultural University, Mymensingh from July to November 1999. The soil texture was sandy loam with $\mathrm{pH}$ 6.4. The experiment included two factors-storage conditions and storage durations of the uprooted seedlings. Seedlings were kept, $\left(\mathrm{E}_{1}\right)$ under shade of the roof of a threshing floor, $\left(\mathrm{E}_{2}\right)$ in natural sunlight having 13.5 hours duration $\left(\mathrm{E}_{3}\right)$ floating in water with about $5 \mathrm{~cm}$ of the seedling-base submerged Seedlings were transplanted after the storage duration of 0 day $\left(D_{0}\right) 2$ days $\left(\mathrm{D}_{1}\right), 4$ days $\left(\mathrm{D}_{2}\right), 6$ days $\left(\mathrm{D}_{3}\right)$ and 8 days $\left(\mathrm{D}_{4}\right)$. The experiment was laid-out in split plot design, assigning the storage conditions to the main plots and storage duration to the subplots at random. The treatments were replicated 4 times. The spacing between the replications, main plots and unit plots were $1.0 \mathrm{~m}, 0.5 \mathrm{~m}$ and $0.5 \mathrm{~m}$, respectively. The recommended rice cultivar, BR11 (Mukta) was used as the planning material. Its field duration varies from 140 to 150 days and its average yield is 5.6t/ ha. ${ }^{3}$ The seedlings were raised in wet nursery beds where no fertilizer was applied a common practice in Bangladesh. The main crop land was fertilized with urea, triple super phosphate, muriate of potash, gypsum and zinc sulphate at the rates of $150,90,80,60$, and $10 \mathrm{Kg} / \mathrm{ha}$, respectively as per the recommendation of BRRI. ${ }^{4}$ The full dose of triple super phosphate, muriate of potash, gyjpsum and zinc sulphate and one third of urea were applied at the time of the final land preparation. The rest of the urea was top dressed in two equal splits at 42 and 64 days after transplanting (at maximum tillering stage and panicle initiation stages) respectively. The sprouted rice seeds were sown in the nursery bed on 4 July, 1999. The seedlings were uprooted carefully from the nursery bed on 10(36 days), 12 (38 days), 14(44 days), 16(42 days) and 18(44 days) August and stored for 8,6,4,2 and 0 days, respectively as per the design of the experiment. Transplanting was done on 18 August using 44-day-old seedlings at the rate of 3 seedlings per hill, maintaining the spacing of $20 \mathrm{~cm}$ and $15 \mathrm{~cm}$ between the rows and hills, respectively. Identical 
intercultural operations were done in each unit plot as and when required. The crop was harvested plot wise on 25 November 1999 (99 days after transplanting) at full maturity. Ten hills per plot were selected randomly prior to harvest. The plants of the hills were uprooted carefully for collecting data on crop characteristics.

The data on the following plant characteristics and yield components were collected:
i) Number of hills/plot
ii) Number of culms $/ \mathrm{m}^{2}$
iii) Plant height $(\mathrm{cm})$
iv) Number of fertile tillers/hill
v) Number of infertile tillers/hill
vi) Panicle length $(\mathrm{cm})$
vii) Thousand grain weight(g)
viii) Grain yield(t/ha)
ix) Straw yield(t/ha)
x) Harvest index (\%)

The analysis of variance for various crop characteristics was done following the principle of F-test, and Duncan's New Multiple Range Test (DMRT) was used to adjust the significant values.

\section{RESULTS AND DISCUSSION}

\section{Effect of storage conditions:}

Table 1 shows the effect of storage conditions on some of the characteristics of the uprooted seedlings. The storage conditions had significant effects on the number of hills/plot. Among the three storage conditions, the highest number (259.4) of hills/plot was noted when the seedlings were stored in water. This was followed by those stored under shade and in the sun, the difference being significant in each case. The number of culms $/ \mathrm{m}^{2}$ was also significantly affected by the different storage conditions. The seedlings stored in water produced the highest number of culms of $246 / \mathrm{m}^{2}$, while the lowest number was $214 / \mathrm{m}^{2}$ obtained from the seedlings stored in the sun (Table1). Significant variation was observed in the case of plant height, owing to different storage conditions. The maximum plant height of $104.4 \mathrm{~cm}$ obtained from the seedlings stored in water, was significantly higher than those stored in the sun, which gave the lowest plant height of $97.98 \mathrm{~cm}$ (Table 1). The number of fertile tillers/hill produced by the seedlings stored in water was the maximum (9.12) and it was significantly higher than those produced by the seedlings stored either under shade (8.30) or in the sun (7.70). The number of infertile tillers/ hill produced by the seedling under different storage conditions failed to show any significant difference (Table 1). 


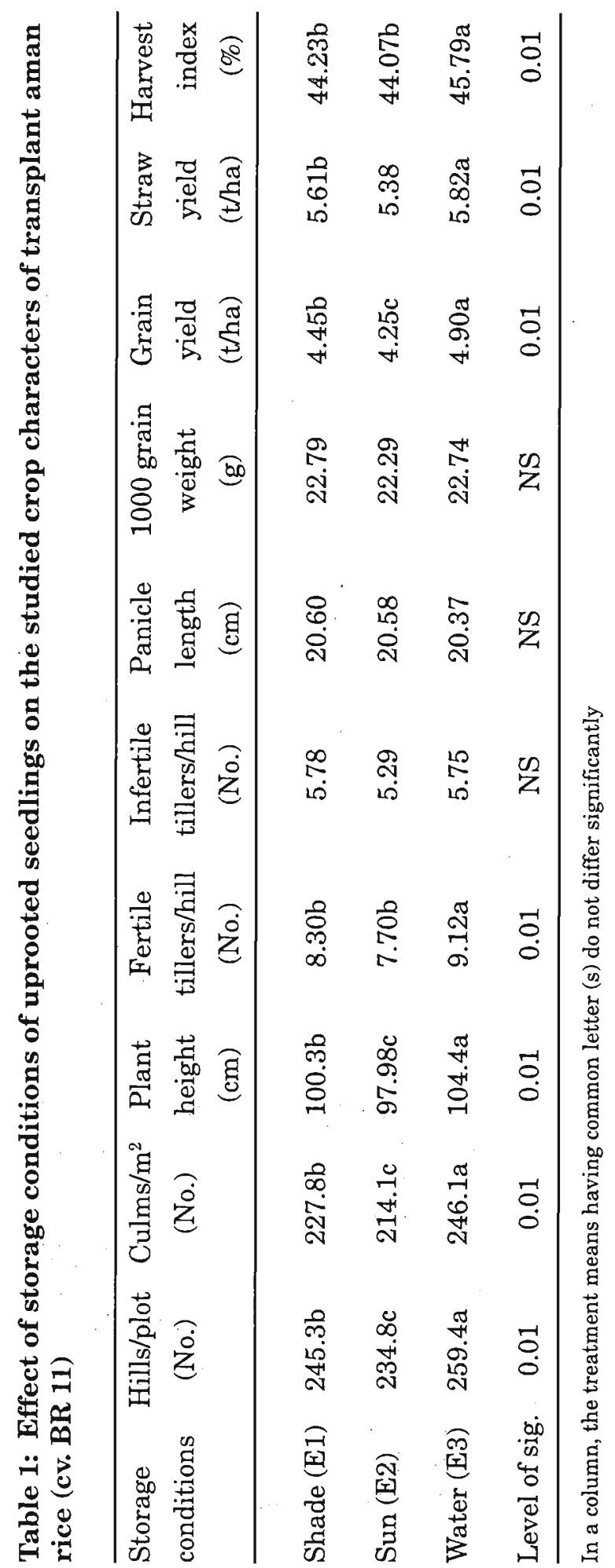


The weight of 1000 grains was also not significantly affected by the conditions of storage viz. under shade, in the sun and in the water. The yield of grain/ha was significantly affected by the storage conditions of uprooted seedlings. The highest yield of $4.90 \mathrm{t} / \mathrm{h}$ a obtained from the seedlings stored in water was significantly higher than that ( $4.45 / \mathrm{ha}$ ) obtained from the seedlings stored in the sun, and the difference in grain yield between the latter two was also significant (Table 1). The highest grain yield/ha obtained from the seedlings stored in water might have been due to the cumulative favourable effect of all the yield contributing character as well as the number of hills/plot and culms $/ \mathrm{m}^{2}$ produced in the same treatment. Straw yield showed a similar trend as the grain yield/ha (Table 1). The effect of the storage condition of uprooted seedlings had a significant effect on the harvest index of the crop. The maximum value of the harvest index (45.79\%) was exhibited by the seedlings stored in water and was significantly higher than those stored under shade $(44.23 \%)$ and in the sun (44.07\%), both of which are identical in respect of the harvest index (Table 1).

\section{Effect of storage durations:}

The storage period of uprooted seedlings of BR11 rice showed significant variation in the number of hills/plot at harvest (Table 2). The maximum number of 265.5 hills/plot was found in the treatment, 0 day of storage, which was identical to that of 2 days of storage, but significantly higher than those of the rest of the storage treatments. This indicates that the survivability of the hills with viable seedlings gradually decreased with the increase in the storage duration of uprooted seedlings before transplanting (Table 2). The number of culms $/ \mathrm{m}^{2}$ at harvest also showed almost the same trend as did the number of hills/plot. The maximum number of $252.7 \mathrm{culms} / \mathrm{m}^{2}$ produced in the treatment, 0 day of storage, was significantly higher than the rest of the treatments (Table 2). The plant height exhibited a trend to decrease with the increase in the storage durations from 0 to 8 days (Table 2). The maximum plant height of $104.0 \mathrm{~cm}$ produced in the treatment, 0 day of storage, was significantly higher than those of the rest of the treatments. The number of both fertile and infertile tillers/hill was significantly affected by different storage durations. The numbers of fertile tillers/hill were the highest (9.68) when stored for 0 day and lowest (7.05) with 8 days of storage. Here the maximum number of infertile tillers/hill(6.73) produced in 0 days of storage, was significantly higher than those of the three different sets of identical storage durations of 2 and 4 days, 4 and 6 days, 6 and 8 days. The effect of storage duration on the panicle length was significant. The length of panicle gradually declined with the increase in the storage duration from 0 to 8 days (Table 2). The highest length of panicle was $(21.17 \mathrm{~cm})$ and a storage duration of 8 days produced a significantly shorter panicle length $(19.71 \mathrm{~cm})$ than those of the rest of the treatments. The weight of 1000 grains was also significantly affected due to variation in the storage duration. Here, the highest weight $(23.60 \mathrm{~g})$ of 1000 grains obtained from 0 day of storage was significantly higher than those of the rest of the treatments. The grain yield/ha exhibited a 


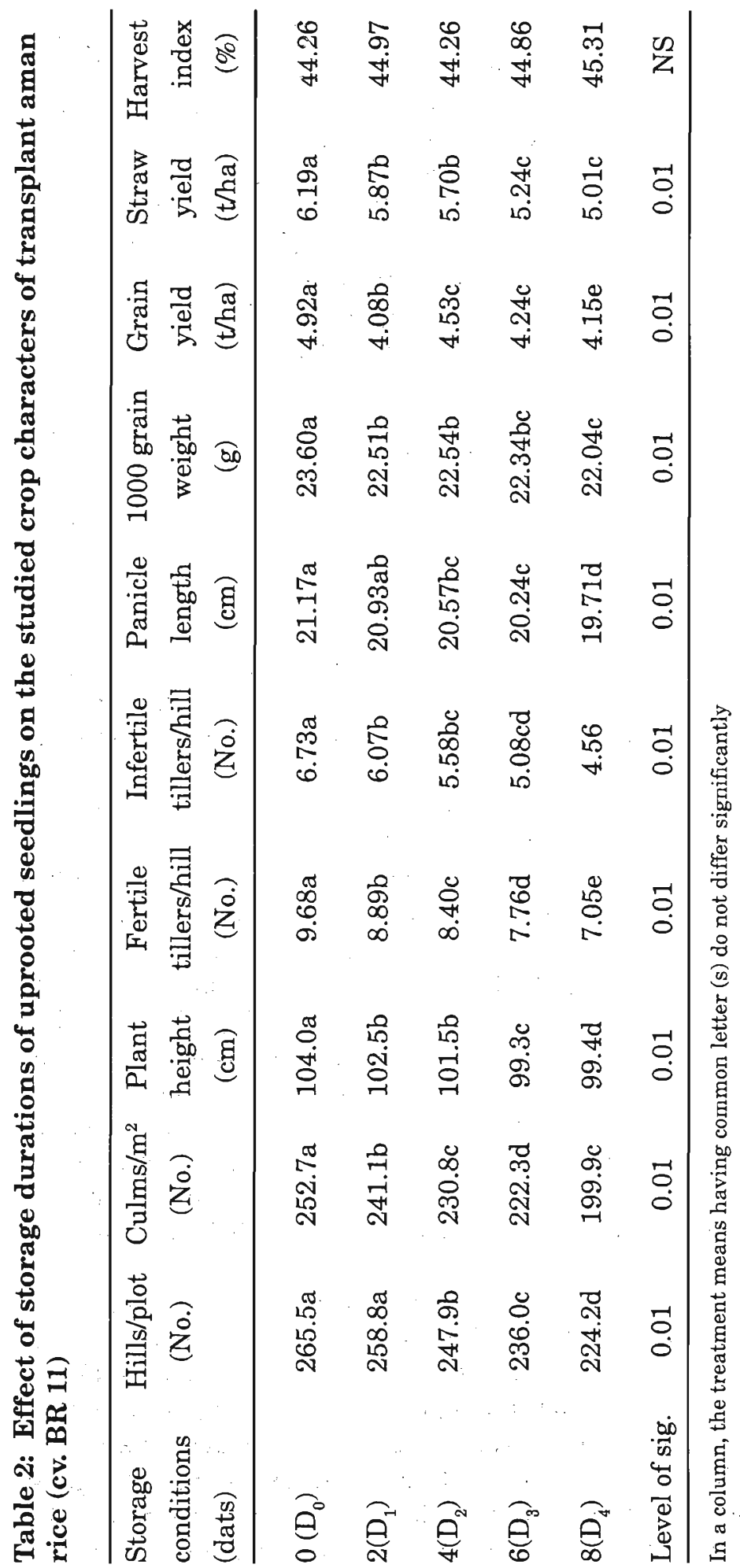


decreasing trend with the increase in the storage duration from 0 to 8 days (Table 2). The maximum grain yield of $4.92 \mathrm{t} / \mathrm{ha}$ obtained from 0 day of storage was significantly higher than those of all other storage durations, and the lowest grain yield (4.15t/ha) produced in the treatment of 8 days of storage. It is to be noted that fresh seedlings transplanted on the same day that they were uprooted gave the highest yield. The delay in transplanting of uprooted seedlings by every 2 days decreased the grain yield significantly. BRRI ${ }^{3}$ reported that more than $3.0 t /$ ha of grain yield was obtained from the 40 day old seedlings stored in water for 7 days, but the 20 day old seedlings stored for the same period in water produced a much lower grain yield of only 1.4t/ha. The findings of the present study area are in partial agreement with those of BRRI. ${ }^{3}$ The yield of straw/ha also showed almost the same trend as the grain yield/ha (Table 2). Seedlings stored for 0 day produced the highest straw yield $(6.19 \mathrm{t} / \mathrm{ha}$ ) and the lowest was found in the treatment of 8 days of storage. Das and Mukharjee. ${ }^{5}$ also obtained similar results from their study. The harvest index varied slightly due to the storage duration and the differences were not great enough to be significant (Table 1).

\section{Effect of interaction of storage conditions and storage duration:}

The effect of interaction of storage conditions and storage duration on the number of hills/plot at harvest was significant (Table 3). The maximum number of 267.3 hills/plot was noted in the treatment where the seedlings were stored in water for 0 day. Gomosta et al. ${ }^{7}$ evaluated the performance of uprooted rice seedlings stored in water and in mud for a number of days. They found that the survivability percentage decreased with the increase in storage duration in the case of water storage. The results obtained from this study are in partial agreement with those of Gomosta et al. ${ }^{7}$ The number of culms $/ \mathrm{m}^{2}$ showed similar trend as the number of hills/plot indicating the superiority of water storage for all the storage durations over other storage conditions (Table 3). The plant height obtained from the treatment combinations of water storage of seedlings for up to 8 days was significantly higher than the rest of the storage conditions (Table 3 ) The number of fertile tillers/hill and the length of panicle did not show any significant effect due to interaction of storage conditions and storage duration of uprooted rice seedlings. The number of infertile tillers/hill, though effected significantly, failed to show any definite trend (Table 3). Though the 1000 grain weight differed in their numerical values due to the effect of interaction of storage conditions and storage durations, the differences among the treatments were not sufficient to be significant (Table 3 ).

The effect of interaction of storage condition and storage duration was significant on the yield of grain/ha. The grain yield/ha was significantly higher in plants stored in water in all the storage durations from 0 to 8 days (Table 3). The reasons for the higher grain yield in the above mentioned treatment combinations might be due to the favourable cumulative effect of the yield contributing characters such as number of hills/plot and number of culms $/ \mathrm{m}^{2}$ in the same treatments. The 
M. A. Haque et al.

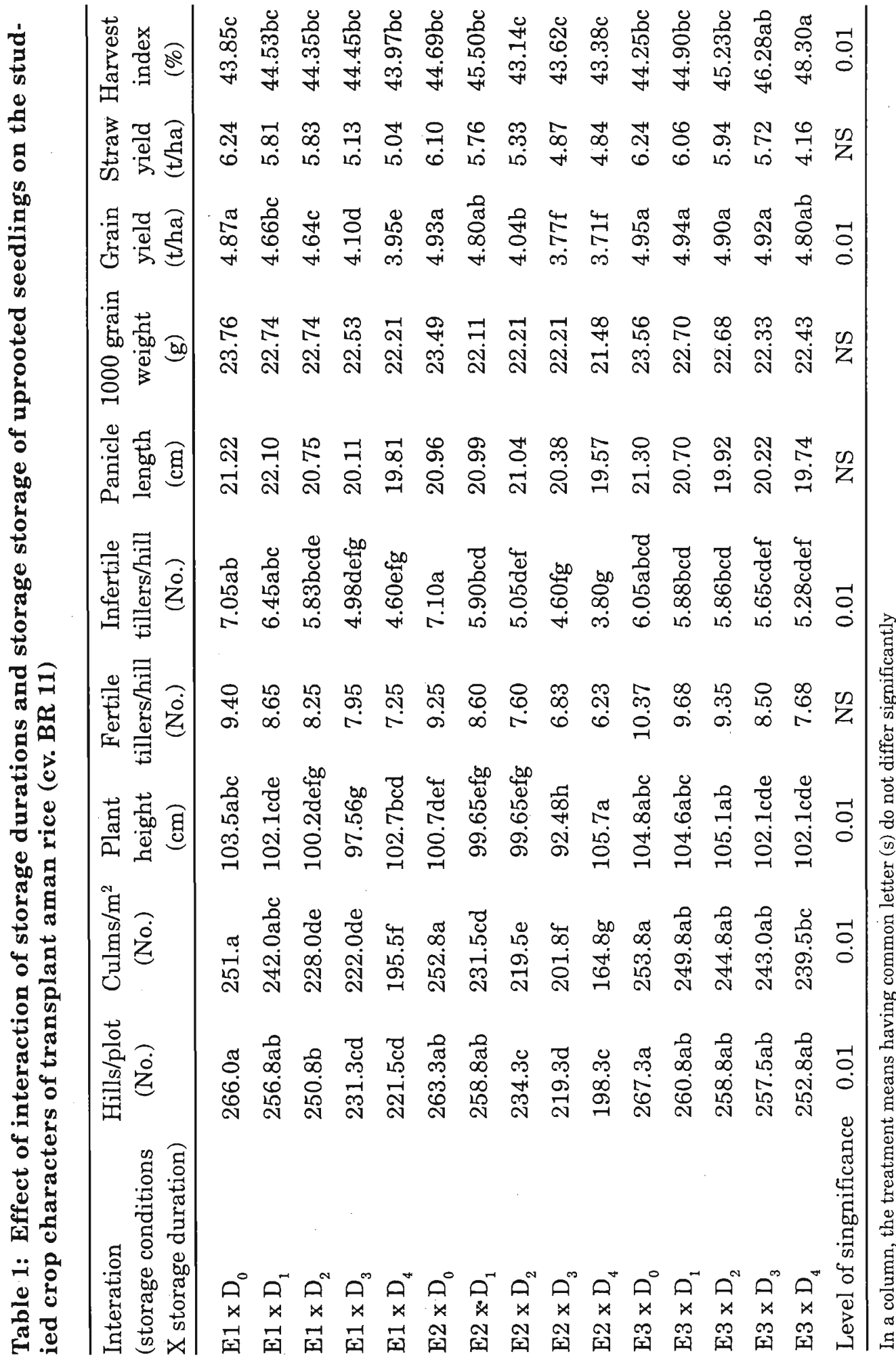


seedlings stored in water might have got a comparatively more favourable environment than the other conditions of storage under shade and in the sun to continue their normal physiological activities even for considerably longer durations of 8 days. It was observed that the yield of straw/ha was not affected by the effect of interaction of storage conditions and storage durations (Table 3). Though the effect of interaction of storage condition and storage durations on harvest index was significant, their trend of effect was dissimilar (Table 3).

From the results obtained, it can be concluded that in case of an emergency, uprooted seedlings BR11 rice can be stored in water even up to 8 days and in the sun or under shade for 0 to 2 days without any appreciable losses in grain yields.

\section{References}

1 Bangladesh Bureau of Statistics (1997). Statistical Year Book of Bangladesh, Statistics Division, Ministry of Planing, Govt. of the People's Republic of Bangladesh. p.143.

2 BRRI(1989). "Adhunik Dhaner Chash" (In Bengali). Bangladesh Rice Research Institute, Joydebpur, Gazipur. p.9.

3 BRRI (1991). The Annual Report for 1988. Bangladesh Rice Research Institute, Joyebpur, Gazipur, pp.1-40.

4 BRRI (1995). "Adhunik Dhaner Chash" (In Bengali). Bangladesh Rice Research Institute, Joydepur, Gazipur pp.1-40.

5 - Das N.R. \& Mukherjee N.N.(1992). Effect of seedling uprooting time and leaf removal on grain and straw yields of rainy season rice (Oryza sativa L.) Indian Journal of Agronomy 37(1 \& 2): 167-169.

$6 \quad$ FAO (1995). Production Year Book FAO, UN, Rome, 49:70-71.

7 Gomosta A.R., Quayyum H.A., Molla A. H. \& Haque M.Z. (1990). Storage of seedlings for transplant aman rice. Bangladesh Rice Journal 1(1): 55-63.

8 Hossain S.M.A. (1988). Agricultural and Rural Development in Bangladesh, evolution of cropping system in Mymensingh and Commilla Regions, Japan Int, Co-op Agency, Dhaka JSARD pub. No. 12:27. 